\title{
Golgi phosphoprotein 3 (GOLPH3) promotes hepatocellular carcinoma progression by activating mTOR signaling pathway
}

Hongying Liu ${ }^{1+}$, Xieqi Wang ${ }^{3 \dagger}$, Bing Feng ${ }^{2}$, Lipeng Tang ${ }^{2}$, Weiping Li ${ }^{1}$, Xirun Zheng ${ }^{1}$, Ying Liu ${ }^{1}$, Yan Peng ${ }^{1}$, Guangjuan Zheng ${ }^{1,2^{*}}$ and Qinglian $\mathrm{He}^{1 *}$ (D)

\begin{abstract}
Background: Hepatocellular carcinoma (HCC) is the sixth most common cancer and the second leading cause of cancer-related deaths worldwide. Despite new technologies in diagnosis and treatment, the incidence and mortality of HCC continue rising. And its pathogenesis is still unclear. As a highly conserved protein of the Golgi apparatus, Golgi phosphoprotein 3 (GOLPH3) has been shown to be involved in tumorigenesis of HCC. This study aimed to explore the exact oncogenic mechanism of GOLPH3 and provide a novel diagnose biomarker and therapeutic strategy for patients with HCC.

Methods: Firstly, the expression of GOLPH3 was detected in the HCC tissue specimens and HCC cell lines. Secondly, RNA interference was used for GOLPH3 gene inhibition. Thirdly, cell proliferation was analyzed by MTT; cell apoptosis was analyzed by Annexin-V/PI staining, Hoechst 33,342 staining and caspase 3/7 activity assay. Fourthly, xenograft tumor model was used to study the function of GOLPH3 in tumor growth in vivo. Finally, western blotting and immunohistochemistry were used to investigate the role of GOLHP3 in the mTOR signaling pathway.

Results: Data showed that the mRNA and protein expression of GOLPH3 were up-regulated in HCC tumor tissue and cell lines compared with those of control $(P<0.05)$. Correlation analyses showed that GOLPH3 expression was positively correlated with serum alpha-fetoprotein level (AFP, $P=0.006$ ). Knockdown GOLPH3 expression inhibited proliferation and promoted apoptosis in HCC cell lines. What's more, knockdown GOLPH3 expression led to tumor growth restriction in xenograft tumor model. The expression of phosphorylated mTOR, AKT and S6 K1 were significantly higher in HCC tumor tissue and cell lines compared with those in normal liver tissues $(p<0.05)$. While the phosphorylated mTOR, AKT and S6 K1 were much lower when diminished GOLPH3 expression in HCC cell lines both in vitro and in vivo.

Conclusion: The current study suggests that GOLPH3 contributes to the tumorigenesis of HCC by activating mTOR signaling pathway. GOLPH3 is a promising diagnose biomarker and therapeutic target for HCC. Our study may provide a scientific basis for developing effective approaches to treat the HCC patients with GOLPH3 overexpression.
\end{abstract}

Keywords: GOLPH3, Hepatocellular carcinoma, mTOR signaling pathway

\footnotetext{
*Correspondence: zhengguangjuan@163.com; heqinglian65@163.com

${ }^{\dagger}$ Hongying Liu, and Xieqi Wang contributed equally to this work.

'Department of Pathology, The Second Clinical College of Guangzhou

University of Chinese Medicine,Guangdong Provincial Hospital of Chinese

Medicine, 111 Dade Road, Guangzhou 510120, Guangdong, China

Full list of author information is available at the end of the article
}

(c) The Author(s). 2018 Open Access This article is distributed under the terms of the Creative Commons Attribution 4.0 International License (http://creativecommons.org/licenses/by/4.0/), which permits unrestricted use, distribution, and reproduction in any medium, provided you give appropriate credit to the original author(s) and the source, provide a link to the Creative Commons license, and indicate if changes were made. The Creative Commons Public Domain Dedication waiver (http://creativecommons.org/publicdomain/zero/1.0/) applies to the data made available in this article, unless otherwise stated. 


\section{Background}

Hepatocellular carcinoma (HCC) is one of the most common solid tumors with second cancer-related lethal rate worldwide [1]. Compared with the most solid cancers, the incidence and mortality of HCC have increased over the past decades in many parts of the world. Especially in China, HCC accounts for one-fifth of the incidence of malignant tumors [2]. In clinic, HCC can be treated with surgical resection, liver transplantation, interventional therapy, liver directed therapy and systemic therapy. Among these options, only surgical resection and liver transplantation are considered as potentially curative approaches. However, only $15 \%$ patients are eligible with effective treatment while a majority is present with advanced disease [3]. Therefore, developing more efficient therapies that based on the precise pathogenesis of $\mathrm{HCC}$ is critical for the clinical management of HCC. With rapid advances in the molecular biology of HCC, several prognostic biomarkers are identified, including alpha fetoprotein (AFP) [4, 5], glypican-3 [6], des- $\gamma$-carboxyprothrombin (DCP) [7], cytokeratin 19 [8] and so on. Even though these biomarkers are used widely in some countries, there are still shortages for clinical diagnosis and prognosis predication. It is reported that elevation in AFP level is not evident in around $80 \%$ of small HCC [9]. In HCC patients, the specificity of serum DCP-based diagnosis was 81$98 \%$, but the sensitivity was only $48-62 \%$ [10]. And recent studies have showed that cell-free DNA (cfDNA) is associated with oncogenesis and cancer progression, which can be used as a biomarker [11]. However, clinical significance of cfDNA needs to be futher confirmed. So, these limitations highlight the necessity and urgency to find additional biomarkers that can be used individually or combined with other markers for HCC diagnosis.

Known as GPP34/GMx33/MIDAS in animal, Golgi phosphoprotein 3 (GOLPH3) is a highly conserved phosphorylated protein expressed on the Golgi apparatus [12]. It is encoded by a gene residing on human chromosome 5p13, which is frequently amplified in multiple solid tumor types [13]. Recent studies have demonstrated that GOLPH3 is an oncogene involved in the development and progression of several tumor types including lung cancer [14, 15], breast cancer [16], melanoma [13], colon cancer [17], bladder cancer [18], gastric cancer $[19,20]$, prostate cancer [21], oral tongue cancer [22], rhabdomyosarcoma [23], glioma [24] and so on. Especially several studies have demonstrated that high expression of GOLPH3 is associated with poor survival in patients with $\mathrm{HCC}[25,26]$. However, the exact pathological mechanism of GOLPH3 in the tumorigenesis of $\mathrm{HCC}$ is still ambiguous. A better understanding of the activity and mechanism of GOLPH3 will contribute to explore cancer pathogenesis, and provide novel targets and therapeutic strategies for patients with HCC. It has been elucidated that GOLPH3 can regulate cell size, enhance growth-factor-induced mTOR signaling in many human cancer cell lines like A549 and CRL-5889, and alter the response to rapamycin which is a mTOR inhibitor in vivo [13]. However, whether GOLPH3 can promote HCC progression by activating mTOR signaling is still unknown. The objectives of this study were to investigate the relationship between GOLPH3 and mTOR signaling pathway in $\mathrm{HCC}$.

\section{Methods}

\section{Patients and tissue samples}

The HCC tissue specimens, including HCC tissues and adjacent normal liver tissues, were obtained from Guangdong Provincial Hospital of Chinese Medicine (GPHCM) between 2011 and 2016. None of the patients who participated in this study received any pre-operative treatments, including TACE or radiofrequency ablation. Their clinicopathological characteristics were collected. Histological type and grade were established according to the World Health Organization (WHO) standards and further independently evaluated by two experienced pathologists. Immunohistochemistry (IHC) and quantitative real-time PCR (qPCR) were used to analyze the expression of GOLPH3 in both tumor tissues and adjacent normal liver tissues (not less than $2 \mathrm{~cm}$ away from the tumor tissues). This study was approved by the Ethic Committee of GPHCM.

\section{Cells and cell cultures}

Hepatocellular carcinoma cell lines, including Bel-7402 (catalogue number TCHu 10), QGY-7703 (catalogue number $\mathrm{TCHu}$ 43), MHCC97L (catalogue number CC0109), MHCC97H (catalogue number SCSP 528) were cultured in RPMI 1640 (Gibco BRL, Rockville, MD) supplemented with 10\% fetal bovine serum (Gibco BRL, Rockville, MD), penicillin (100 units/ml) and streptomycin (100 units/ml), and maintained in a $5 \%$ $\mathrm{CO}_{2}$-humidified incubator at $37{ }^{\circ} \mathrm{C}$. All cell lines were purchased from the Cell Bank of the Chinese Academy of Sciences (Shanghai, China).

\section{Immunohistochemistry (IHC) analysis}

IHC analysis on $4 \mu \mathrm{m}$ paraffin-embedded specimens sections was performed by using Ventana Benchmark autostainer (Roche Diagnostics, Indianapolis, IN, USA), according to the best protocol for each antibody tested in our laboratory. The primary antibody for mTOR (catalogue number 2983), phospho-mTOR (Ser2448) (catalogue number 5536), AKT (catalogue number 4691) , phospho-AKT (Ser473) (catalogue number 4060), S6 K1 (catalogue number 2708), phospho-S6 K1 (Thr389) (catalogue number 9234) were purchased from 
Cell Signaling Technology (CST) (Boston, MA, USA), GOLPH3 (catalogue number ab98023) was purchased from Abcam (Cambridge, MA, USA). Slides were viewed and photographed under a light microscope, and analyzed by using Image-Pro Plus software (version 6.2) program (Media Cybernetics). The intensity of staining was graded as follows: 0 (no staining), 1 (weak staining, light yellow), 2 (moderate staining, yellow brown) and 3 (strong staining, brown). The proportion of positive tumor cells were scored according to the following standards: $1(<10 \%), 2(10-35 \%), 3(35-70 \%)$ and $4(>70 \%)$. The staining index was determined by multiplying the intensity score by the proportion score. A staining index score of $\geq 6$ was designated as tumors with high GOLPH3 expression, whereas a score of $\leq 4$ was designated as low GOLPH3 expression.

\section{Quantitative real-time PCR analysis (qPCR)}

Total RNA from formalin-fixed paraffin-embedded tissues was extracted by using nucleic acid extraction kit (AmoyDx, China) according to the manufacturer's protocol. And total RNA was extracted from cultured cells by using the RNAiso plus reagent (TaKaRa, Japan). Total RNA was reverse transcribed by using Primescript $^{\text {tw }}$ RT reagent kit gDNA Eraser (TaKaRa, Japan). qPCR was performed by using SYBR Premis Ex $\mathrm{Tag}^{\mathrm{TM}} \mathrm{II}(\mathrm{TaKaRa}$, Japan) on the 7500 qPCR System (Applied Biosystems Inc., Foster City, CA, USA).The qRCR reactions were pre-incubated for $10 \mathrm{~min}$ at $95^{\circ} \mathrm{C}$, followed by 40 cycles of denaturation for $30 \mathrm{~s}$ at $95^{\circ} \mathrm{C}$ and annealing for $1 \mathrm{~min}$ at $60{ }^{\circ} \mathrm{C}$. The primers for amplifying GOLPH3 are as follows: 5'-GGGCGACTCCAAG GAAAC-3' (forward) and 5'-CAGCCACGTAATCCAGATGAT-3' (reverse), and primers to amplify GAPDH contains: 5'-AGCCACATCGCTCAGACACC-3' (forward) and 5'-CGCCCAATACGACCAAATCC-3' (reverse). Reactions containing either no reverse transcriptase or no template were used as negative controls, and all reactions were performed in triplicate. The GAPDH was used as the normalization control, and the relative expression level was calculated using the $2-{ }^{\Delta \Delta \mathrm{CT}}$ equation.

\section{Western blotting analysis}

Cells were washed twice with PBS and lysed by using RIPA lysis buffer (CWBIO, China) containing protease inhibitor cocktail (Thermo, Rockford, IL, USA) and phosphatase inhibitor (Calbiochem, Billerica, MA, USA). The extracts were then subjected to centrifugation at $15,000 \times \mathrm{g}$ for $30 \mathrm{~min}$ at $4{ }^{\circ} \mathrm{C}$. And protein concentration was determined by using BCA protein assay kit (Thermo, Rockford, IL, USA). Total proteins $(40 \mu \mathrm{g})$ from each sample with loading buffer were heated at $100{ }^{\circ} \mathrm{C}$. Samples were separated by using SDS-PAGE and electro-transferred to polyvinylidene fluoride membranes
(Millipore, Billerica, MA, USA). Membranes were blocked with TBS-T containing 5\% skimmed milk at room temperature for $1 \mathrm{~h}$. Membranes were then incubated with primary antibodies in TBS-T overnight at $4{ }^{\circ} \mathrm{C}$ on shaker. Washed with TBS-T, the membranes were incubated secondary antibody for $1 \mathrm{~h}$ at room temperature following day. The expression of proteins were detected with the Molecular Imager ChemiDoc XRS and Image Lab 5.2.1 software (Bio-Rad Laboratories, Hercules, USA) following various exposure times. And Image J software was used to quantify the density of the bands. For western blotting, primary polyclonal antibodies against GOLPH3 (1:2000 dilution), mTOR (1:2000 dilution), p-mTOR (1: 2000 dilution), AKT (1:2000 dilution), p-AKT (1:2000 dilution), S6 K1 (1:2000 dilution), p-S6 K1 (1:2000 dilution), Raptor (1:1000 dilution, Proteintech, catalogue number 20984-1-AP), Rictor (1:1000 dilution, Santa Cruz, catalogue number sc-271081), DNA-PKcs (1:1000 dilution, Santa Cruz, catalogue number sc-390849), Ku70 (1:1000 dilution, Santa Cruz, catalogue number sc-17789) and Ku86 (1:1000 dilution, Santa Cruz, catalogue number sc5280) were used. GAPDH antibody (1:5000 dilution, CST, catalogue number 5174) and $\beta$-actin (1:5000 dilution, CST, catalogue number 4970) served as the internal control.

\section{RNA interference}

For transient knockdown GOLPH3, MHCC97L and MHCC97H cells were grown in 6-well plates and transfected with GOLPH3 siRNA (si-GOLPH3) (Guangzhou Ribo Biotechnology Co., Ltd.) or a control siRNA (siCtrl) (Guangzhou Ribo Biotechnology Co., Ltd.) by using Lipofectamine RNAiMAX reagent (Invitrogen, USA) according to the manufacturer's instructions. To generate stable GOLPH3 knockdown cells, GOLPH3 RNAi lentivirus plasmids were cotransfected into $293 \mathrm{~T}$ cells with GV248, Helper 1.0 and Helper 2.0. Viral supernatant fractions were collected at $48 \mathrm{~h}$ after transfection and filtered through a $0.45 \mu \mathrm{m}$ filter followed by infection into MHCC97L and MHCC97H cells together with $5 \mu \mathrm{g} / \mathrm{mL}$ polybrene. After $12 \mathrm{~h}$ infection, the medium was replaced with fresh medium containing $2 \mu \mathrm{g} / \mathrm{mL}$ puromycin and cells were incubated for another 6 days. Western blotting and qPCR were used to verify downregulated GOLPH3.

\section{3-(4,5-dimethylthiazol-2-yl)-2,5-diphenyltetrazolium bromide (MTT) assays}

Cells $\left(5 \times 10^{3}\right.$ cells/well) were plated into 96 -well plates and each well was incubated with $20 \mu \mathrm{l} 5 \mathrm{mg} / \mathrm{ml}$ MTT (Sigma-Aldrich) at $37^{\circ} \mathrm{C}$ for $4 \mathrm{~h}$. Absorbance was measured at $490 \mathrm{~nm}$ by using a microplate reader (Biotek, USA). Cells incubated with culture medium were used 
as the control group. Each sample was assayed in triplicate.

\section{Annexin V-FITC/PI staining}

Apoptosis assay was performed by Annexin V-FITC/PI apoptosis kit (Multi science, China) according to the manufacturer's protocol. Transfected HCC cells were washed twice in PBS and resuspended in binding buffer. The cells were then stained with AnnexinV-FITC and propidium iodide (PI) for $5 \mathrm{~min}$ in dark and followed by FACS analysis by using FC500 (Beckman Coulter, USA).

\section{Hoechst 33,342 staining}

Cells $\left(1 \times 10^{4}\right.$ cells/well) were plated in 12 -well plates and then transfected with si-GOLPH3 or si-Ctrl for 144 h. $10 \mu \mathrm{l}$ Hoechst 33,342 (5 mg/ml; Beyotime, Jiangsu, P.R.China) was added to plate. After $10 \mathrm{~min}$, cells were washed twice in PBS and observed in a fluorescence microscope (Nikon-TE2000U, Tokyo, Japan).

\section{Caspase $3 / 7$ activity assay}

Caspase-Glo 3/7 assay (Promega, Madison, WI, USA) was used to measure the activation of caspase 3 and caspase 7 . Cells $\left(5 \times 10^{3}\right.$ cells/well $)$ were seeded in 96-well white plate. Transfected cells were incubated in the $\mathrm{CO}_{2}$ incubator at $37{ }^{\circ} \mathrm{C}$ for $144 \mathrm{~h}$. $100 \mu \mathrm{l}$ Caspase-Glo 3/7 reagent was added and the plate was kept at room temperature for $3 \mathrm{~h}$ in dark prior to luminescence detection.

\section{Xenograft tumor model}

Male Balb/c nude mice (aged 4-5 weeks, weight 1820 g) (Beijing Vital River Laboratory Animal Technology Co., Ltd., Beijing, China) were housed in barrier facilities on a $12 \mathrm{~h}$ light/dark cycle. All experimental procedures were approved by the Institutional Animal Care and Use Committee of GPHCM. The Balb/c nude mice were randomly divided into four groups ( $n=7$ for each group), inoculated subcutaneously with $5 \times 10^{6}$ stable LV-Ctrl or LV-GOLPH3-RNAi MHCC97L cells and LV-Ctrl or LVGOLPH3-RNAi MHCC97H cells. The tumor length (L) and width (W) were measured with calipers every two days, and tumor volumes were calculated by using the eq. $\left(\mathrm{L} \times \mathrm{W}^{2}\right) / 2$. The animals of MHCC $97 \mathrm{~L}$ groups or $\mathrm{MHCC} 97 \mathrm{H}$ groups were sacrificed after five or four weeks respectively and tumor tissues were collected.

\section{Statistical analysis}

Statistical analysis was conducted by using SPSS 20.0 software (International Business Machine, Armonk, NY, USA). Results expressed as mean \pm standard deviation (SD) were analyzed by using the Student's two-tailed ttest. The associations between GOLPH3 protein expression and clinicopathological variables were analyzed by using the chi-square test. The $P$ value was based on the two-sided statistical analysis and $P<0.05$ was considered statistically significant.

\section{Results}

GOLPH3 is overexpressed in HCC tissue samples and HCC cell lines

To investigate whether the high expression of GOLPH3 is linked to HCC, the expression of GOLPH3 was examined. Firstly, the mRNA and protein expression of GOLPH3 in 60 pairs of paraffin-embedded HCC and adjacent normal liver tissue samples were detected. GOLPH3 mRNA was over-expressed in HCC tumor tissues compared with that in corresponding adjacent normal liver tissues (Fig. 1a). Then, the GOLPH3 protein level of HCC samples were examined by IHC. Results showed that the GOLPH3 protein level of HCC tissues were significantly higher than that of adjacent normal liver tissues $(P<0.001)$ (Fig. 1b). From the statistical data, 42 of $60(70.0 \%)$ samples were classified as HCC with high GOLPH3 protein expression, but only 18 of 60 (30.0\%) samples were designated as HCC with low GOLPH3 protein expression (Table 1). This result clearly indicated that most HCC patients had a higher probability of over-expressed GOLPH3 in tumor tissue. The mRNA and protein expression of GOLPH3 were further detected in four HCC cell lines. Result showed that the mRNA and protein of GOLPH3 were much higher in $\mathrm{HCC}$ cell lines than those of control (Fig. 1c and Fig. 1d). These results implicated that GOLPH3 might be a critical molecule in HCC development.

\section{Correlation between GOLPH3 expression and clinicopathological characteristics}

The correlation between the expression of GOLPH3 and clinicopathological characteristics of the HCC patients were analyzed by using the chi-square test (Table 1). The expression of GOLPH3 was found to be associated with serum AFP level $(P=0.006)$. It indicated that patients with high GOLPH3 expression had a higher tendency to have higher serum AFP level, which is the main serum marker of HCC. However, no significant correlation was observed between GOLPH3 expression and any other clinicopathological characteristics, such as gender, age, $\mathrm{HBsAg}$, tumor size, vascular invasion and cirrhosis.

\section{Knockdown GOLPH3 inhibits the HCC cell proliferation and promotes the HCC cell apoptosis}

To examine the function of GOLPH3, we knocked down GOLPH3 gene in MHCC97L and MHCC97H cells by GOLPH3 siRNA. The silence efficiency of GOLPH3 siRNA was verified by qPCR and western blotting. As our data showed, compared with that in the control 


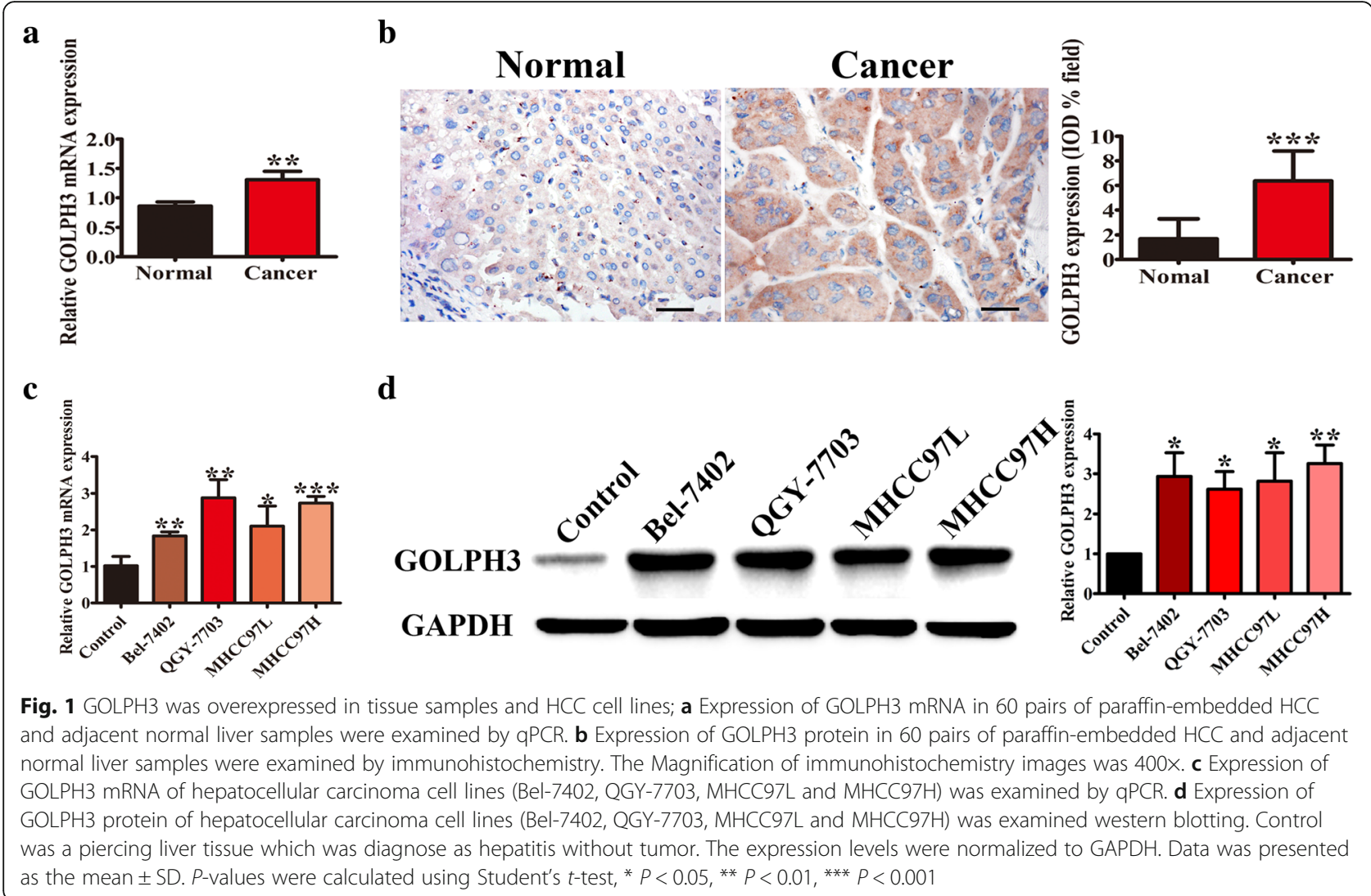

group, the relative expression of GOLPH3 mRNA and protein was significantly decreased in the GOLPH3 siRNA transfected group at $48 \mathrm{~h}, 96 \mathrm{~h}$ and $144 \mathrm{~h}(P<0.05)$ (Fig. 2a and Fig. 2b). MTT assays demonstrated that knockdown of endogenous GOLPH3 expression significantly reduced HCC cells proliferation compared with corresponding control siRNA cells especially at $144 \mathrm{~h}$ (Fig. 2c). In addition, Annexin V-fluorescein isothiocyanate (FITC)-propidium iodide (PI) staining indicated that the knockdown of GOLPH3 significantly promoted the apoptosis in MHCC97L and MHCC97H cells compared with control cells at $144 \mathrm{~h}$ (Fig. 2d). And this result was further confirmed by Hoechst 33,342 staining (Fig. 2e). Moreover, it was indicated that caspase-3/7, two terminal executioners in apoptosis, were activated in HCC cell lines transfected with GOLPH3 siRNA (Fig. 2f). Taking together, these results demonstrated that diminishment of GOLPH3 expression significantly reduced the tumorigenic properties of HCC cells in vitro.

\section{GOLPH3 contributes to the progression of HCC in vivo}

The ability of GOLPH3 to promote HCC progression was further examined by using a xenograft tumor model. The stable GOLPH3 knockdown cells were generated. And the results showed that the tumors in the LV-Ctrl group grew faster than those in the LV-GOLPH3-RNAi group (Fig. 3a).
The average tumor weights were decreased in the LVGOLPH3-RNAi group (Fig. 3b). The tumor volumes were decreased in the LV-GOLPH3-RNAi group (Fig. 3c). In addition, IHC staining indicated that both the percentage of Ki67-positive cells and MVD were decreased in GOLPH3 knockdown tumors, which indicated that down-regulation of GOLPH3 inhibited tumor cells proliferation and tumor progression in vivo (Fig. 3d). All these results suggested that knocked down GOLPH3 expression significantly reduced the tumorigenic properties of HCC cells in vivo.

\section{GOLPH3 activates the mTOR signaling in HCC both in vitro and in vivo}

It is reported that GOLPH3 can promote tumor growth via activating mTOR signaling pathway [13]. To test whether GOLPH3 could also promote the progression of HCC by activating mTOR signaling pathway, we examined the expression of key proteins involved in mTOR singling pathway including mTOR, AKT and S6 K1. Firstly, the expression of phosphorylated-mTOR, AKT and S6 K1 in HCC tissue specimens and cell lines were investigated by IHC and western blotting respectively. The data showed that the level of phosphorylated mTOR, AKT and S6 K1 were significantly higher in HCC tumor tissues than those of adjacent normal liver tissues (Fig. 4a). And western blotting analysis showed 
Table 1 Correlation between GOLPH3 protein expression and clinicopathological characteristics of hepatocellular carcinoma

\begin{tabular}{|c|c|c|c|c|}
\hline \multirow[t]{2}{*}{ Clinicopathological characteristics } & \multirow[t]{2}{*}{ Number of cases } & \multicolumn{2}{|c|}{ GOLPH3 expression } & \multirow[t]{2}{*}{$P$-value } \\
\hline & & Low & High & \\
\hline Gender & & & & 0.288 \\
\hline Male & 39 & 14 & 25 & \\
\hline Female & 21 & 4 & 17 & \\
\hline Age(years) & & & & 0.302 \\
\hline$\leq 50$ & 26 & 6 & 20 & \\
\hline$>50$ & 34 & 12 & 22 & \\
\hline Tumor size & & & & 0.220 \\
\hline$\leq 5 \mathrm{~cm}$ & 38 & 14 & 24 & \\
\hline$>5 \mathrm{~cm}$ & 22 & 4 & 18 & \\
\hline AFP levels & & & & $\left.0.006^{*}\right)$ \\
\hline$\leq 20 \mathrm{ng} / \mathrm{ml}$ & 21 & 11 & 10 & \\
\hline$>20 \mathrm{ng} / \mathrm{ml}$ & 39 & 7 & 32 & \\
\hline $\mathrm{HBsAg}$ & & & & 0.1 \\
\hline negative & 27 & 11 & 16 & \\
\hline positive & 33 & 7 & 26 & \\
\hline Vascular invasion & & & & 0.186 \\
\hline Absence & 36 & 8 & 28 & \\
\hline Presence & 24 & 10 & 14 & \\
\hline Liver cirrhosis & & & & 0.071 \\
\hline Absence & 31 & 13 & 18 & \\
\hline Presence & 29 & 5 & 24 & \\
\hline
\end{tabular}

$P$-value was calculated by using chi-square test. ${ }^{*} P<0.05$ indicates a significant association among the variables

that phosphorylated mTOR, AKT and S6 K1 level were dramatically higher in the HCC cell lines compared with those in the control group (Fig. 4b). What's more, knockdown GOLPH3 down-regulated the phosphorylation of mTOR, AKT and S6 K1 in MHCC97L and MHCC97H (Fig. 5a). These results were further confirmed in xenograft tumor model (Fig. 5b). In our supplementary material, we also discovered that in HCC cell lines, knockdown GOLPH3 inhibited the expression of Raptor, which is a specific element of mTORC1. However, silencing GOLPH3 has no effect on the expression of Rictor, one component of mTORC2. (Additional file 1: Figure S1A). Collectively, these data provided strong biochemical evidence that GOLPH3 exerted a pivotal role in promoting the progression of $\mathrm{HCC}$ by activating mTOR signaling pathway.

\section{Discussion}

This study demonstrated that GOLPH3 was significantly over-expressed in human HCC tumor tissues. In addition, high expression of GOLPH3 was closely correlated with the serum AFP level, a widely used serum marker of HCC. In vitro, we found that the downregulation of GOLPH3 resulted in decreasing cell proliferation and increasing cell apoptosis. Moreover, diminished GOLPH3 could inhibit tumorigenic properties of HCC cells in vivo. Furthermore, mTOR signaling pathway was involved in the pathological mechanism of GOLPH3 in HCC.

Hepatocellular carcinoma (HCC) is a cancer with a high mortality rate due to the fact that diagnosis usually occurs at an advanced stage. So it remains a serious threat to human health. Over the past decades, no significant improvements have been achieved regarding the early diagnosis and treatment of HCC. The understanding of the molecular oncogenesis underlying HCC is still lacking. Many studies have showed that GOLPH3 is an oncogene, which is involved in tumorigenesis and correlated with poor prognosis. Furthermore, some previous studies report that GOLPH3 overexpression is associated with poor clinical outcome in $\operatorname{HCC}[25,26]$. In this study, we also discovered that GOLPH3 was high expressed in the HCC tumor tissues (Fig. 1). It is reported that HCC patients with AFP level $\leq 20 \mathrm{ng} / \mathrm{ml}$ may benefit the most from hepatectomy, but patients with AFP level $>20 \mathrm{ng} / \mathrm{ml}$ need comprehensive therapy, surgical resection and close follow-up examinations [27]. So we put the $20 \mathrm{ng} / \mathrm{ml}$ AFP as a 

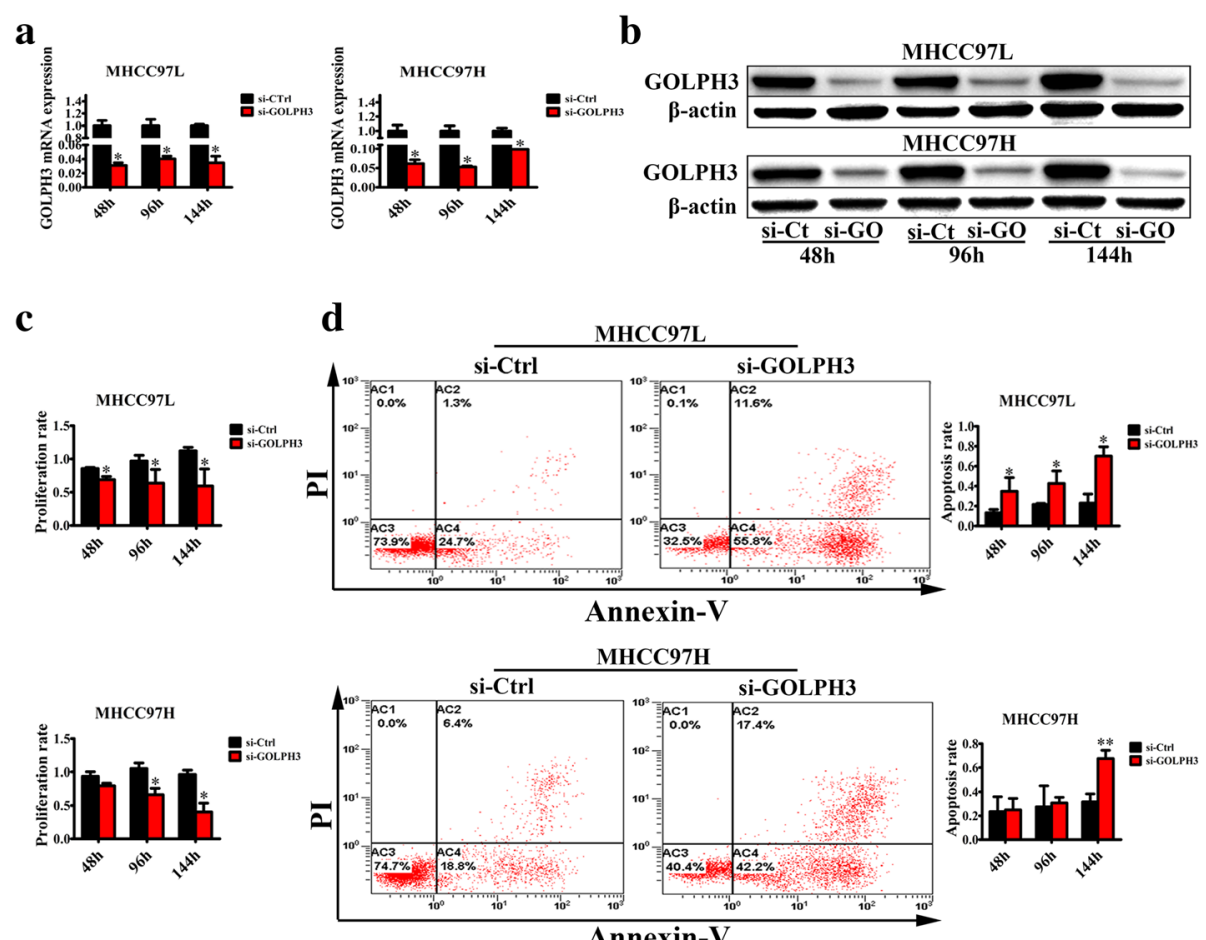

e
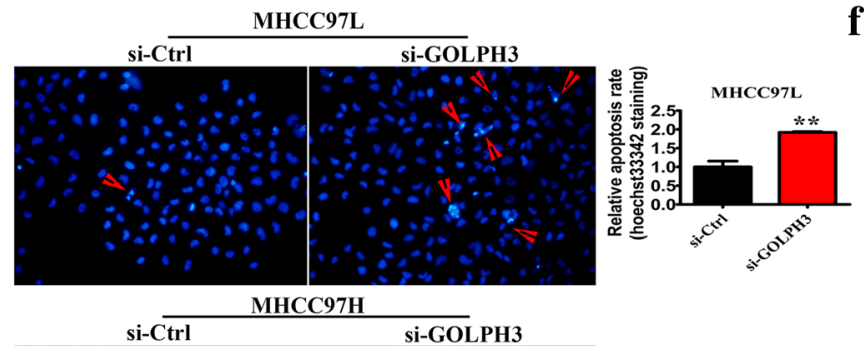

f
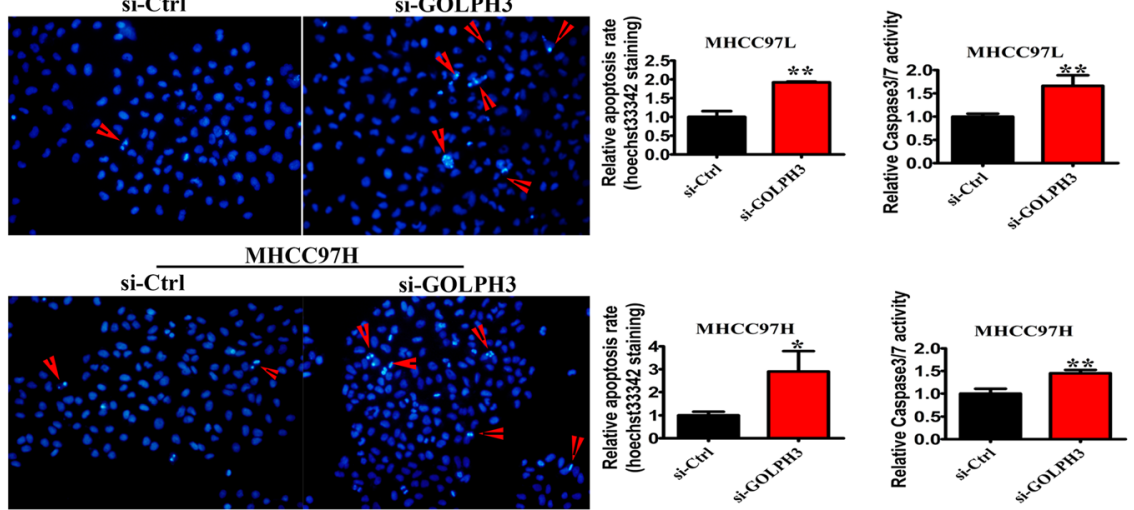

Fig. 2 GOLPH3 depletion inhibited the HCC cells proliferation and promoted the HCC cells apoptosis; a The relative expression of GOLPH3 mRNA in MHCC97L and MHCC97H cells transfected with si-GOLPH3 for 48 h, 96 h and 144 h. b The relative expression of GOLPH3 protein in MHCC97L and MHCC97H cells transfected with si-GOLPH3 for 48 h, 96 h, and 144 h. And si-Ct, si-GO represented si-Ctrl, si-GOLPH3 respectively. c MTT assay of HCC cells transfected with si-GOLPH3 for 48 h, 96 h and 144 h. d Flow cytometry for Annexin V-fluorescein isothiocyanate (FITC)-propidium iodide (PI) staining of the HCC cells treated with si-GOLPH3 for different time. e Hoechst 33,342 staining of HCC cells transfected with si-GOLPH3 after $144 \mathrm{~h}$. The magnification of images was 400x. f Caspase3/7 activity assay of the HCC cells after transfected with si-GOLPH3 for $144 \mathrm{~h}$. All experiments were performed in triplicate with at least three independent experiments. Data was presented as the mean \pm SD. $P$-values were calculated using Student's t-test, ${ }^{*} P<0.05,{ }^{* *} P<0.01,{ }^{* *} P<0.001$, significant difference compared with the si-Ctrl cells in the same time

standard. And the results showed that the upregulation of GOLPH3 was strongly correlated with high AFP level (Table 1). What's more, that low expression of GOLPH3 promoted HCC cell apoptosis and inhibited tumorigenesis was found by functional studies in vitro and in vivo (Fig. 2 and Fig. 3).

However, to our knowledge, the precise mechanisms underlying the relationship between GOLPH3 and HCC are still rarely understood. Only one research has indicated that GOLPH3 can play a critical role in HCC aggressiveness and angiogenesis by activating the NF-kB signaling pathway [26]. In 2009, Scott et al. demonstrated that GOLPH3 could promote tumor growth via activating mTOR signaling pathway [13]. But it is unclear that whether this phenomenon also occurs in HCC or not. 


\section{$\mathbf{a}$

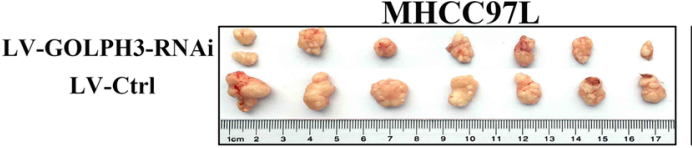

МНСC97H

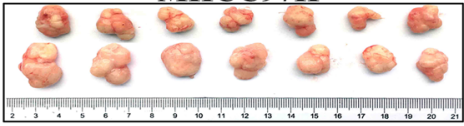

b

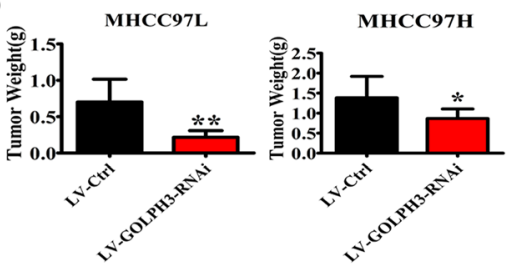

c
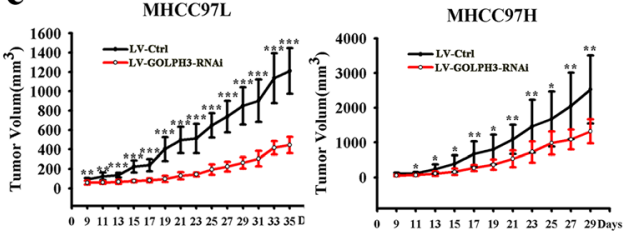

d
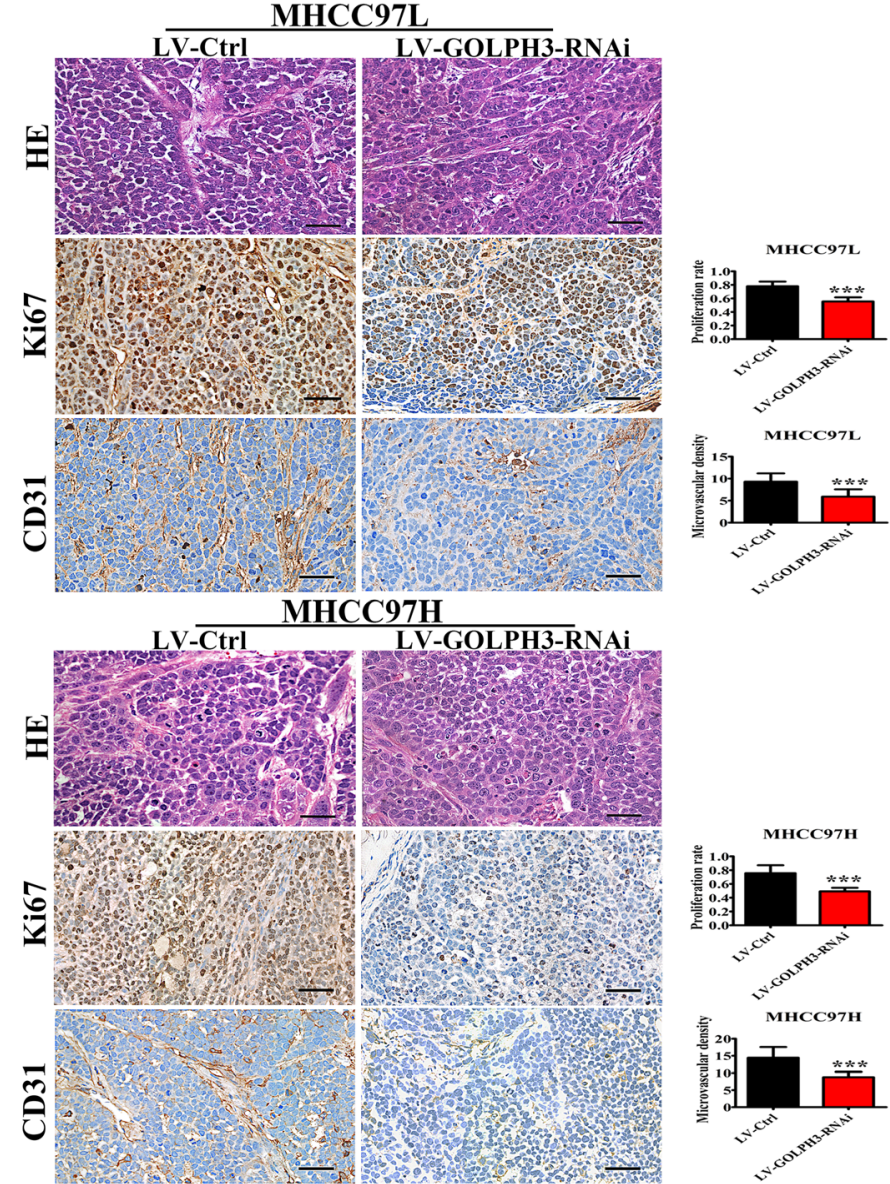

Fig. 3 GOLPH3 contributed to the progression of HCC in vivo; a Photographs of tumors dissected from mice $(n=7)$ injected with LV-GOLPH3RNAi or LV-Ctrl HCC cells. $\mathbf{b}$ Average tumors weight of mice from each group was shown. $\mathbf{c}$ Volume growth curves for the tumors formed by the HCC cells transfected with LV-GOLPH3-RNAi or LV-Ctrl. $\mathbf{d}$ HE staining and expression of Ki67 and CD31 in tumors tissue formed by the HCC cells transfected with LV-Ctrl or LV-GOLPH3-RNAi. The magnification of images was 400x. All experiments were performed in triplicate with at least three independent experiments. Data were presented as the mean \pm SD. $P$-values were calculated using Student's t-test, ${ }^{*} P<0.05, * *$ $P<0.01$, *** $P<0.001$, significant difference compared with the LV-Ctrl group

The mammalian target of rapamycin (mTOR), a phosphatidylinositol 3 kinase (PI3K)-related serine/theronine kinase, plays a central role in regulating cell growth, proliferation and survival, in part by regulating translation initiation. mTOR functions in two structural and functional distinct protein complexes: mTORC1, which also contains two positive regulatory subunits, Raptor and
mLST8, and two negative regulators, PRAS40 and DEPTOR; and mTORC2, which also contains Rictor, mSin1 and Protor, and also mLST8 and DEPTOR [28-32]. As a part of mTOR complexes, mTORC1 directly activates S6 K1 (p70 ribosomal protein S6 kinase), phosphorylated at Thr389 [33, 34], the major rapamycin-sensitive site. S6 K1 clearly plays an important role in the regulation of 


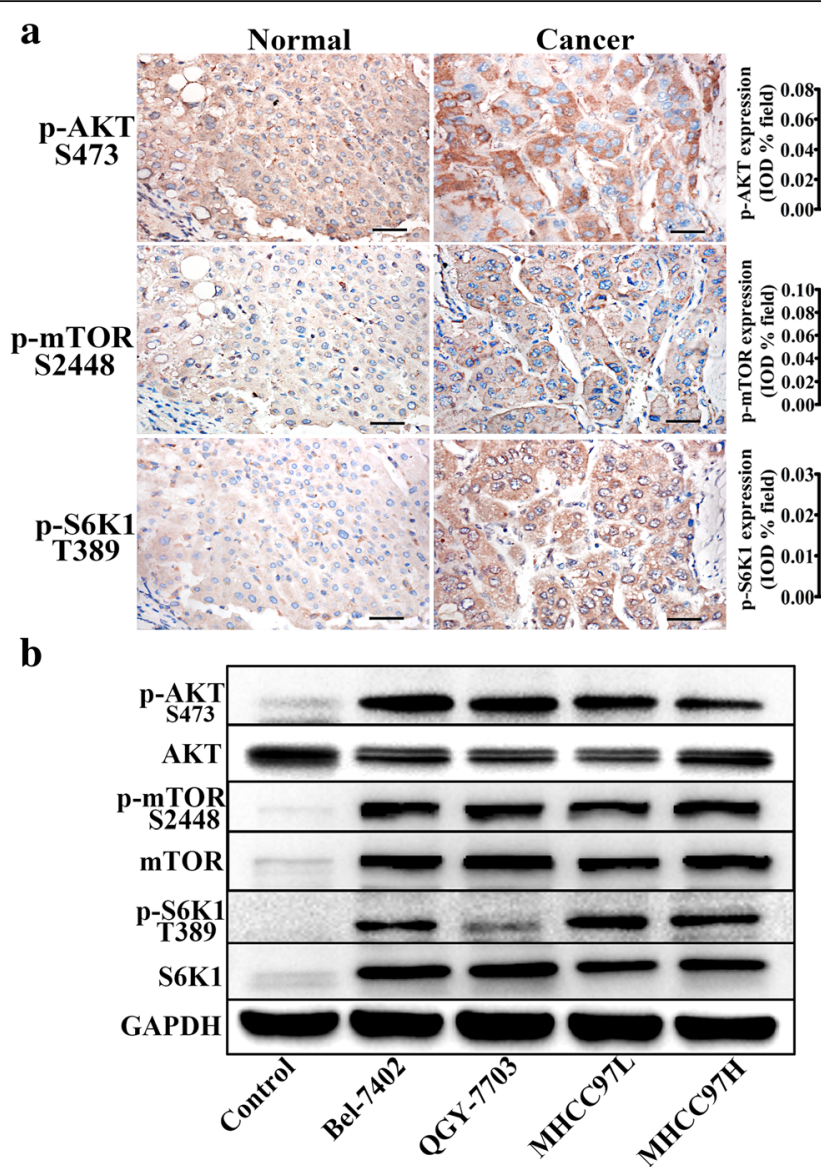

Fig. 4 mTOR signaling pathway was activated in HCC; a Immunohistochemistry of p-AKT (Ser473), p-mTOR (Ser2448), and p-S6 K1 (Thr389) in HCC clinic samples, the magnification of images was 400x; b Western blotting of AKT, p-AKT (Ser473), mTOR, p-mTOR (Ser2448), S6 K1 and pS6 K1 (Thr389) in hepatocellular carcinoma cell lines (Bel-7402, QGY-7703, MHCC97L and MHCC97H). Control was a piercing liver tissue which was diagnose as hepatitis without tumor. The expression levels were normalized to GAPDH. All experiments were performed in triplicate with at least three independent experiments. Data were presented as the mean \pm SD. $P$-values were calculated using Student's t-test, ${ }^{*} P<0.05,{ }^{* *} P<0.01,{ }^{* * *} P<0.001$

cell growth, cell cycle progression and cell proliferation [31]. While mTORC2 was found to play a critical role in phosphorylating Akt (Ser473), which is one of the most important survival kinases, involved in regulating a wide array of cellular processes, including metabolism, growth, proliferation and apoptosis [35-37]. In the HCC tissue specimens, immunochemistry revealed that the protein expression of p-mTOR (Ser2448), p-Akt (Ser473), and p-S6 K1 (Thr389) in the HCC tumor tissues were significantly higher than those in the paired normal groups (Fig. 4a). These results were verified in HCC cell lines (Fig. 4b). What's more, by knocking down the GOLPH3 expression in HCC cells, the expression of p-mTOR (Ser2448), p-Akt (Ser473) and p-S6 K1 (Thr389) were remarkably decreased in the HCC cell lines and in the xenograft tumor model (Fig. 5a and Fig. 5b). These results indicated that GOLPH3 could be involved in HCC tumorigenesis via activating both mTORC1 and mTORC2. For further study, we also noted that knockdown GOLPH3 in the HCC cell lines diminished expression of Raptor rather than Rictor (see Additional file 1: Figure S1A). Research has suggested that Raptor can regulate mTOR activity and functions as a scaffold for recruiting mTORC1 substrates [38]. Perhaps GOLPH3 could regulate Raptor to activate mTOR signaling cascade in HCC. Studies have demonstrated that mTOR controls NF-kB activity by stimulating IKK [39] and GOLPH3 could sustain the activation of the NF- $\mathrm{KB}$ signaling pathway in HCC [26]. Thus, the interplay among GOLPH3, mTOR and NF- $\mathrm{kB}$ in the progression of HCC is likely to be complex and needs to be further investigated. What's more, research has shown that DNA-PK, a multimeric complex consisting of a catalytic subunit, DNA-PKcs, and the regulatory subunits, Ku70 and Ku86, plays a critical role in the DNA damage response, particularly in the recognition and repair of double stranded breaks [40]. DNA-PK could phosphorylate GOLPH3 and play an important role in DNA-PK/ GOLPH3/MYO18A pathway to regulate cell survival following DNA damage [41]. In addition, Hemmings and 


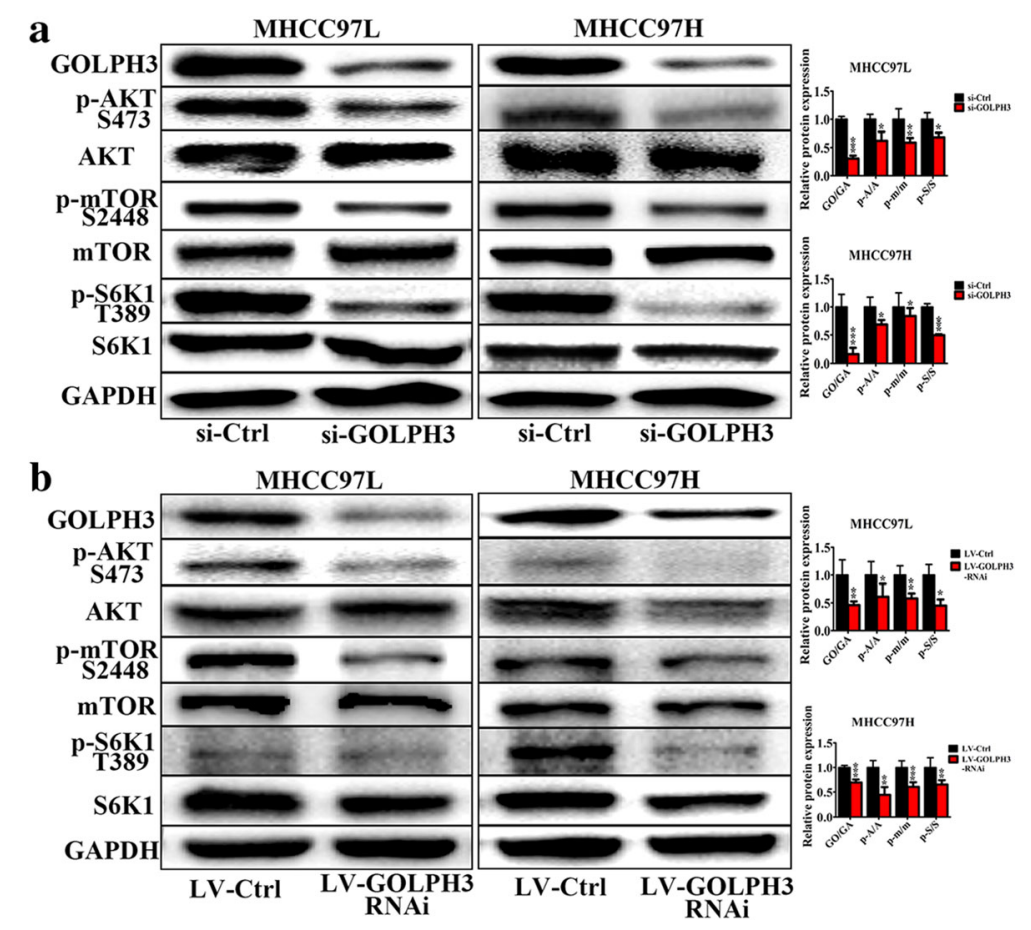

Fig. 5 Knockdown of GOLPH3 inactivated mTOR signaling pathway in HCC in vitro and in vivo; a Western blotting of AKT, p-AKT (Ser473), mTOR, p-mTOR (Ser2448), S6 K1 and p-S6 K1 (Thr389) in MHCC97L and MHCC97H cells transfected with si-Ctrl and si-GOLPH3. b Western blotting of AKT, p-AKT (Ser473), mTOR, p-mTOR (Ser2448), S6 K1 and p-S6 K1 (Thr389) in Xenograft tumor model injected with LV-Ctrl or LV-GOLPH3-RNAi HCC cells. The expression levels were normalized to GAPDH. In Column diagram, GO, GA, A, p-A, m and p-m means GOLPH3, GAPDH, AKT, p-AKT, mTOR and p-mTOR respectively. All experiments were performed in triplicate with at least three independent experiments. Data were presented as the mean \pm SD. $P$-values were calculated using Student's t-test, ${ }^{*} P<0.05,{ }^{*} P<0.01,{ }^{* *} P<0.001$

colleagues observed that DNA-PK could phosphorylate AKT on Ser473 [42]. And in our study, we discovered that when knocking down the GOLPH3 expression in HCC cells, the expression of DNA-PKcs and Ku70 was decreased (Additional file 1: Figure S1B). Perhaps this was because GOLPH3 and DNA-PK could via regulating the phosphorylation of AKT influence each other in Golgi's function during DNA damage response. The more exact mechanism between DNA-PK/GOLPH3/MYO18A pathway and GOLPH3/mTOR pathway to regulate function of GOLPH3 in HCC progression will be explored in our further studies. And we think it is likely that there exist one or more proteins involved in GOLPH3-associated xsignaling pathway in $\mathrm{HCC}$ which may have therapeutic utility.

\section{Conclusions}

This study illustrates that the expression of GOPLH3 is pivotal in HCC by activating mTOR signaling pathway, which has emerged as an attractive therapeutic target for cancer therapy. Based on these results, we propose that the inhibition of GOLPH3-mTOR signaling pathway may represent a novel target for $\mathrm{HCC}$ therapy.

\section{Additional file}

Additional file 1: Figure S1. GOLPH3 depletion inhibited Raptor and DNA-PK expression. (A) Western blotting of Raptor and Rictor in MHCC97L and MHCC97H cells transfected with si-Ctrl and si-GOLPH3. (B) Western blotting of DNA-PKCs, Ku70 and Ku86 in MHCC97L and MHCC97H cells transfected with si-Ctrl and si-GOLPH3. The expression levels were normalized to GAPDH. Data were presented as the mean \pm SD. $P$-values were calculated using Student's t-test, ${ }^{*} P<0.05,{ }^{*} P<0.01$, *** $P<0.001$. (TIF $9945 \mathrm{~kb}$ )

\section{Abbreviations}

AFP: a-fetoprotein; DNA-PK: DNA damage protein kinase; GOLPH3: Golgi phosphoprotein 3; HCC: hepatocellular carcinoma;

IHC: immunohistochemistry; mTOR: mammalian target of rapamycin; mTORC1: mammalian target of rapamycin complex 1; mTORC2: mammalian target of rapamycin complex 2; MTT: 3-(4,5-dimethylthiazol-2-yl)-2,5diphenyltetrazolium bromide; qPCR: quantitative real-time PCR;

Raptor: regulatory associated protein of mTOR; Rictor: rapamycin insensitive companion of mTOR; S6 K1: p70 ribosomal protein 56 kinase

\section{Funding}

The design of this study, western blotting, cell transfections and animal experiments were supported by the Science and Technology Planning Project of Guangdong Province, China (grant No. 2014A020212264), while proliferation, apoptosis and GPCR assays were supported by the National Natural Science Foundation of China (grant No. 81403142 and No. 81602748), Clinical samples' collection and immunostaining were sponsored by Special fund of Guangdong Provincial Hospital of Chinese Medicine for scientific and technological research of traditional Chinese medicine (grant No. YK2013B2N09). 


\section{Availability of data and materials}

The datasets used and/or analyzed are available from the corresponding author on reasonable request.

\section{Authors' contributions}

QLH and GJZ conceived and designed the research; HYL and XQW performed the transfection, western blotting, xenograft tumor model; BF and LPT performed proliferation, apoptosis experiments; WPL and YP provided clinical specimens, completed IHC analysis; XRZ and YL performed completed $\mathrm{qPCR} ; \mathrm{HYL}, \mathrm{XQW}, \mathrm{BF}, \mathrm{LPT}$, WPL, XRZ, YL and YP analyzed the data as well as interpreted the results. HYL drafted the manuscript; QLH and GJZ critically reviewed and revised the manuscript. QLH, GJZ, LPT and BF acquired the funding. All authors read and approved the final manuscript.

\section{Ethics approval}

This study was approved by Ethics Committee of Guangdong Provincial Hospital of Chinese Medicine (NO.B2017-130-01). And the application for waiver of one or more elements informed consent was approved by Ethics Committee of Guangdong Provincial Hospital of Chinese Medicine. All animal procedures were approved by the Institutional Animal Care and Use Committee of Guangdong Provincial Hospital of Chinese Medicine (NO.2016036).

\section{Competing interests}

The authors declare that they have no competing interests.

\section{Publisher's Note}

Springer Nature remains neutral with regard to jurisdictional claims in published maps and institutional affiliations.

\section{Author details}

'Department of Pathology, The Second Clinical College of Guangzhou University of Chinese Medicine,Guangdong Provincial Hospital of Chinese Medicine, 111 Dade Road, Guangzhou 510120, Guangdong, China. ${ }^{2}$ Department of Pharmacology of Traditional Chinese Medicine, The Second Clinical College of Guangzhou University of Chinese Medicine,Guangdong Provincial Hospital of Chinese Medicine, 111 Dade Road, Guangzhou 510120, Guangdong, China. ${ }^{3}$ Guangzhou University of Chinese Medicine, 232 Waihuan East Road, Guangzhou 510006, China.

Received: 2 November 2017 Accepted: 30 April 2018 Published online: 18 June 2018

\section{References:}

1. Ferlay J, Soerjomataram I, Dikshit R, Eser S, Mathers C, Rebelo M, Parkin DM, Forman D, Bray F. Cancer incidence and mortality worldwide: sources, methods and major patterns in GLOBOCAN 2012. Int J Cancer. 2015;136(5): E359-86.

2. Chen W, Zheng R, Baade PD, Zhang S, Zeng H, Bray F, Jemal A, Yu XQ, He J. Cancer statistics in China, 2015. CA Cancer J Clin. 2016;66(2):115-32.

3. Roxburgh P, Evans TR. Systemic therapy of hepatocellular carcinoma: are we making progress? Adv Ther. 2008;25(11):1089-104

4. Spangenberg HC, Thimme R, Blum HE. Serum markers of hepatocellular carcinoma. Semin Liver Dis. 2006;26(4):385-90.

5. Tateyama M, Yatsuhashi H, Taura N, Motoyoshi Y, Nagaoka S, Yanagi K, Abiru S, Yano K, Komori A, Migita K, et al. Alpha-fetoprotein above normal levels as a risk factor for the development of hepatocellular carcinoma in patients infected with hepatitis C virus. J Gastroenterol. 2011;46(1):92-100.

6. Tangkijvanich P, Chanmee T, Komtong S, Mahachai V, Wisedopas N, Pothacharoen $\mathrm{P}$, Kongtawelert $\mathrm{P}$. Diagnostic role of serum glypican-3 in differentiating hepatocellular carcinoma from non-malignant chronic liver disease and other liver cancers. J Gastroenterol Hepatol. 2010;25(1):129-37.

7. Tsugawa D, Fukumoto T, Kido M, Takebe A, Tanaka M, Kuramitsu K, Matsumoto I, Ajiki T, Koyama T, Ku Y. The predictive power of serum alphafetoprotein and des-gamma-Carboxy prothrombin for survival varies by tumor size in hepatocellular carcinoma. Kobe J Med Sci. 2016;61(5):E124-31.

8. Lee Jl, Lee JW, Kim JM, Kim JK, Chung HJ, Kim YS. Prognosis of hepatocellular carcinoma expressing cytokeratin 19: comparison with other liver cancers. World J Gastroenterol. 2012;18(34):4751-7.
9. Saffroy R, Pham P, Reffas M, Takka M, Lemoine A, Debuire B. New perspectives and strategy research biomarkers for hepatocellular carcinoma. Clin Chem Lab Med. 2007:45(9):1169-79.

10. Marrero JA, Su GL, Wei W, Emick D, Conjeevaram HS, Fontana RJ, Lok AS. Des-gamma carboxyprothrombin can differentiate hepatocellular carcinoma from nonmalignant chronic liver disease in american patients. Hepatology. 2003;37(5):1114-21.

11. Liao W, Mao Y, Ge P, Yang H, Xu H, Lu X, Sang X, Zhong S. Value of quantitative and qualitative analyses of circulating cell-free DNA as diagnostic tools for hepatocellular carcinoma: a meta-analysis. Medicine (Baltimore). 2015;94(14):e722.

12. Wu CC, Taylor RS, Lane DR, Ladinsky MS, Weisz JA, Howell KE. GMx33: a novel family of trans-Golgi proteins identified by proteomics. Traffic. 2000; 1(12):963-75.

13. Scott KL, Kabbarah O, Liang MC, Ivanova E, Anagnostou V, Wu J, Dhakal S, Wu M, Chen S, Feinberg T, et al. GOLPH3 modulates mTOR signalling and rapamycin sensitivity in cancer. Nature. 2009;459(7250):1085-90.

14. Tang W, Han M, Ruan B, Jin W, Lou J, Yuan X, Chen D, Chen Y, Shin W, Jin $\mathrm{H}$, et al. Overexpression of GOLPH3 is associated with poor survival in nonsmall-cell lung cancer. Am J Transl Res. 2016;8(4):1756-62.

15. Lu M, Tian Y, Yue WM, Li L, Li SH, Qi L, Hu WS, Gao C, Si LB, Tian H. GOLPH3, a good prognostic indicator in early-stage NSCLC related to tumor angiogenesis. Asian Pac J Cancer Prev. 2014;15(14):5793-8.

16. Zeng Z, Lin H, Zhao X, Liu G, Wang X, Xu R, Chen K, Li J, Song L. Overexpression of GOLPH3 promotes proliferation and tumorigenicity in breast cancer via suppression of the FOXO1 transcription factor. Clin Cancer Res. 2012;18(15):4059-69.

17. Zhou B, Wang G, Gao S, Chen Y, Jin C, Wang Z, Yang Y, Ma Z, Zhang $W$, Feng $X$. Expression of GOLPH3 protein in colon cancer tissues and its association with the prognosis of patients. Oncol Lett. 2016;12(5): 3936-40.

18. Zhang Q, Zhuang J, Deng Y, Zhao X, Tang B, Yao D, Zhao W, Chang C, Lu $\mathrm{Q}$, Chen $\mathrm{W}$, et al. GOLPH3 is a potential therapeutic target and a prognostic indicator of poor survival in bladder cancer treated by cystectomy. ONCOTARGET. 2015;6(31):32177-92.

19. Hu BS, Hu H, Zhu CY, Gu YL, Li JP. Overexpression of GOLPH3 is associated with poor clinical outcome in gastric cancer. Tumour Biol. 2013;34(1):515-20.

20. Peng J, Fang Y, Tao Y, Li K, Su T, Nong Y, Xie F, Lai M. Mechanisms of GOLPH3 associated with the progression of gastric cancer: a preliminary study. PLoS One. 2014;9(10):e107362.

21. Li W, Guo F, Gu M, Wang G, He X, Zhou J, Peng Y, Wang Z, Wang X. Increased expression of GOLPH3 is associated with the proliferation of prostate Cancer. J Cancer. 2015;6(5):420-9.

22. Li H, Guo L, Chen SW, Zhao XH, Zhuang SM, Wang LP, Song LB, Song M. GOLPH3 overexpression correlates with tumor progression and poor prognosis in patients with clinically NO oral tongue cancer. J Transl Med. 2012:10:168.

23. Kunigou O, Nagao H, Kawabata N, Ishidou Y, Nagano S, Maeda S, Komiya S, Setoguchi T. Role of GOLPH3 and GOLPH3L in the proliferation of human rhabdomyosarcoma. Oncol Rep. 2011;26(5):1337-42.

24. Zhou J, Xu T, Qin R, Yan Y, Chen C, Chen Y, Yu H, Xia C, Lu Y, Ding X, et al. Overexpression of Golgi phosphoprotein-3 (GOLPH3) in glioblastoma multiforme is associated with worse prognosis. J Neuro-Oncol. 2012;110(2): 195-203.

25. Hu GS, Li YQ, Yang YM, Shi W, Liao AJ, Yao YH, Zeng B, Yuan J. High expression of Golgi phosphoprotein-3 is associated with poor survival in patients with hepatocellular carcinoma. Tumour Biol. 2014;35(9): 8625-32.

26. Dai T, Zhang D, Cai M, Wang C, Wu Z, Ying Z, Wu J, Li M, Xie D, Li J, et al. Golgi phosphoprotein 3 (GOLPH3) promotes hepatocellular carcinoma cell aggressiveness by activating the NF-kappaB pathway. J Pathol. 2015;235(3): 490-501.

27. Lui KY, Zhao H, Qiu C, Li C, Zhang Z, Peng H, Fu R, Chen HA, Lu MQ. Integrator complex subunit 6 (INTS6) inhibits hepatocellular carcinoma growth by Wnt pathway and serve as a prognostic marker. BMC Cancer. 2017;17(1):644.

28. Manning BD, Cantley LC. AKT/PKB signaling: navigating downstream. Cell. 2007:129(7):1261-74

29. Guertin DA, Sabatini DM. Defining the role of mTOR in cancer. Cancer Cell. 2007:12(1):9-22

30. Yang Q, Guan KL. Expanding mTOR signaling. Cell Res. 2007;17(8):666-81. 
31. Fingar DC, Blenis J. Target of rapamycin (TOR): an integrator of nutrient and growth factor signals and coordinator of cell growth and cell cycle progression. Oncogene. 2004;23(18):3151-71.

32. Populo $H$, Lopes $J M$, Soares $P$. The mTOR signalling pathway in human cancer. Int J Mol Sci. 2012;13(2):1886-918.

33. Burnett PE, Barrow RK, Cohen NA, Snyder SH, Sabatini DM. RAFT1 phosphorylation of the translational regulators p70 S6 kinase and 4E-BP1. Proc Natl Acad Sci U S A. 1998;95(4):1432-7.

34. Isotani S, Hara K, Tokunaga C, Inoue H, Avruch J, Yonezawa K. Immunopurified mammalian target of rapamycin phosphorylates and activates p70 S6 kinase alpha in vitro. J Biol Chem. 1999;274(48):34493-8.

35. Hresko RC, Mueckler M. mTOR.RICTOR is the Ser473 kinase for Akt/protein kinase B in 3T3-L1 adipocytes. J Biol Chem. 2005;280(49):40406-16.

36. Sarbassov DD, Guertin DA, Ali SM, Sabatini DM. Phosphorylation and regulation of Akt/PKB by the rictor-mTOR complex. Science. 2005;307(5712): 1098-101.

37. Hay N. The Akt-mTOR tango and its relevance to cancer. Cancer Cell. 2005: 8(3):179-83.

38. Hara K, Maruki Y, Long X, Yoshino K, Oshiro N, Hidayat S, Tokunaga C, Avruch J, Yonezawa K. Raptor, a binding partner of target of rapamycin (TOR), mediates TOR action. Cell. 2002;110(2):177-89.

39. Dan HC, Cooper MJ, Cogswell PC, Duncan JA, Ting JP, Baldwin AS. Aktdependent regulation of NF-\{kappa\}B is controlled by mTOR and raptor in association with IKK. Genes Dev. 2008;22(11):1490-500,

40. Buschman MD, Rahajeng J, Field SJ. GOLPH3 links the Golgi, DNA damage, and cancer. Cancer Res. 2015;75(4):624-7.

41. Farber-Katz SE, Dippold HC, Buschman MD, Peterman MC, Xing M, Noakes CJ, Tat J, Ng MM, Rahajeng J, Cowan DM, et al. DNA damage triggers Golgi dispersal via DNA-PK and GOLPH3. Cell. 2014;156(3):413-27.

42. Bozulic L, Surucu B, Hynx D, Hemmings BA. PKBalpha/Akt1 acts downstream of DNA-PK in the DNA double-strand break response and promotes survival. Mol Cell. 2008;30(2):203-13.

\section{Ready to submit your research? Choose BMC and benefit from:}

- fast, convenient online submission

- thorough peer review by experienced researchers in your field

- rapid publication on acceptance

- support for research data, including large and complex data types

- gold Open Access which fosters wider collaboration and increased citations

- maximum visibility for your research: over $100 \mathrm{M}$ website views per year 